\title{
Naturaleza jurídica de los atentados en París. ¿Terrorismo o crímenes de guerra? ${ }^{1}$
}

\author{
Legal nature of the crimes at Paris. Terrorism or war crimes?
}

\section{Raúl F. Campusano Droguett}

rcampusano@udd.cl

Master en Derecho, Universidad de Leiden, Países Bajos, Master of Arts, Universidad de Notre Dame, Estados Unidos. Profesor Derecho Internacional Público y Privado, Universidad del Desarrollo.

\section{Luis Hernán Acevedo Espínola}

luishacevedoe@gmail.com

Abogado, Universidad del Desarrollo. Ayudante de la Cátedra de Derecho Internacional Público, Universidad del Desarrollo.

Resumen: En el presente texto buscaremos analizar jurídicamente los atentados ocurridos en París el 13 de noviembre de 2015 reivindicados por la organización criminal yihadista autoproclamada como Estado Islámico. En general, se ha reaccionado calificando dichos atentados como delitos terroristas, calificación la cual buscamos analizar para concluir que no es óptima, comenzando por la inexistencia de definición internacional y deficiencias en definiciones domésticas, pero además considerando problemas en el debido proceso. Proponemos como recalificación a los crímenes de guerra, dando aplicación al Estatuto de Roma y las Convenciones de Ginebra con sus Protocolos Adicionales, comentando además, sobre la viabilidad procesal de esta propuesta.

Palabras Claves: Atentados en París; Terrorismo; Crímenes de Guerra; Estatuto de Roma.

\begin{abstract}
In this text we analyse from a legal point of view, the crimes committed in Paris on November 13 th of 2015 by the criminal organization ISIS. As a general perception, these acts are understood as "acts of terrorism", witch we think it is not the best option, not only because there is not an international definition of "acts of terrorism", but also because the definitions domestic legislation use for such kind of acts are technically wrong and usually affect the due process of law. We think, as a second option, that these acts are actually war crimes under the Rome Statute of 1998 and the Geneva Convention with their Additional Protocols, which could become an effective option under procedure law.
\end{abstract}

Key Words: Crimes at Paris; Acts of Terrorism; War Crimes; Rome Statute.

1 Artículo enviado el 07.11.2016 y aceptado el 31.01.2017.

Número de página no utilizable para citar 


\section{Introducción}

Concretamente, se pretende dar cuenta de los hechos ocurridos en relación con quienes los cometieron y la organización que los reivindicó, para analizar si jurídicamente es válida su calificación como "delitos terroristas" o si acaso habría otra opción de reacción jurídica posible. $\mathrm{Al}$ respecto, sostenemos que califican más bien como crímenes de guerra, conforme al Estatuto de Roma de 1998, opción la cual no solo resulta ajustada a Derecho sino que también resulta más conveniente, tanto desde la perspectiva de la persecución penal como de los derechos de los imputados, así como también resulta una alternativa procesalmente viable.

En efecto, sostenemos que esta opción resulta ajustada a Derecho y resulta más conveniente, pues como se explicará, el cambio en la calificación jurídica de dichos hechos cambia también el estatuto jurídico aplicable, lo cual incluye, por ejemplo, el hecho de que dichos crímenes, a diferencia de los delitos terroristas, son de jurisdicción universal y admiten el juicio de la Corte Penal Internacional con procedimientos que respetan el debido proceso y penas acorde con los derechos humanos (a diferencia de algunas legislaciones nacionales que cambian su estatuto jurídico frente a hechos que califican como terroristas, sin haber un concepto concreto internacional al respecto, y que dichos cambios conllevan numerosas críticas de organismos internacionales por vulneraciones al debido proceso o penas desproporcionadas), pero al mismo tiempo, el cambio en la calificación jurídica y por tanto el régimen jurídico aplicable, impide la prescripción, la amnistía y los indultos, por nombrar algunas consecuencias, sin perjuicio de otras diferencias con las legislaciones penales domésticas en cuanto a la rigidez o flexibilidad del principio de legalidad, las normas sobre participación y autoría, disposiciones sobre la faz subjetiva de los tipos penales o culpabilidad (según si se sigue un análisis finalista o causalista), diferencias en cuanto a la imputabilidad, causales de justificación o exculpantes, así como también en las circunstancias modificatorias de la responsabilidad penal, excluyendo la impunidad como posibilidad (aunque pueda haber absolución).

De este modo, sostenemos que el cambio en su calificación jurídica y por tanto en el régimen jurídico aplicable, resulta ajustado a Derecho y además, conveniente tanto desde la perspectiva de la persecución criminal como desde los derechos de los imputados. Para sostener esta tesis expondremos en primer lugar los hechos concretos, para luego observar su contexto y algunas reacciones, así como cuál sería el sujeto activo. Luego se presentará un breve análisis sobre el concepto de terrorismo bajo el Derecho Internacional y su naturaleza jurídica como delito transnacional y no como nuclear internacional, haciendo presente las consecuencias desventajosas de dicha naturaleza jurídica, para finalmente ajustar los hechos a la calificación de crímenes de guerra conforme al Estatuto de Roma y los Convenios de Ginebra. Para cerrar, expondremos algunos comentarios desde la perspectiva procesal penal internacional, considerando su importancia para la viabilidad o no de esta tesis en la realidad. Finalmente daremos cuenta de algunas conclusiones. 


\section{Relación de los hechos}

Antes de presentar el análisis jurídico respecto de los atentados en París, corresponde detenerse brevemente en la relación de los hechos, por ser éstos el supuesto fáctico que funda nuestro análisis jurídico. Por ello, se debe señalar en primer lugar que los atentados en París consistieron en una serie de ataques cometidos el 13 de noviembre de 2015 en la capital francesa, cometidos en su mayoría por atacantes suicidas y en donde resultaron 137 personas muertas y 415 heridos.

Concretamente, el hecho con mayor cantidad de afectados directos fue el asalto en el teatro Bataclan, durante un recital. En él, el ataque comenzó a las 21:45 hrs. cuando cuatro miembros del Estado Islámico ingresan al teatro armados con fusiles de asalto AK-47 y comienzan a disparar durante diez a quince minutos hacia la multitud, falleciendo cerca de 80 personas, y tomando 120 rehenes a las 22:00 hrs. El ataque se mantuvo hasta las 00:55 hrs. del día siguiente cuando la policía francesa ingresa al teatro, culminando en definitiva a las 00:58 hrs. Los cuatro atacantes también murieron, tres explotando explosivos que llevaban con ellos y uno por un disparo de la policía.

Paralelo a ello, hubo otros ataques, comenzando por los atentados en las cercanías del Estadio de Francia, donde se encontraba el Presidente de la República de Francia, Francois Hollande, junto con el Ministro de RREE de Alemania, Frank-Walter Steinmeier, durante el partido de futbol amistoso entre las selecciones francesa y alemana. Al respecto, hubo tres ataques suicidas, a las 21:16, 21:30 y 21:53 hrs., donde hubo 10 personas afectadas.

Finalmente, también ocurrieron otros ataques, incluyendo en ellos el tiroteo en Le Petit Cambodge desde las 21:20 hrs. falleciendo cuatro personas, y en el restaurante Le Carillon, falleciendo once personas. También hubo un tiroteo en la pizzería La Casa Nostra falleciendo cinco personas, otro en el bar La Belle Équipe en donde fallecieron dieciocho personas, y un último en el Bulevar Voltaire $\mathrm{N}^{\circ} 253$ en donde hubo una explosión suicida pero sin más muertos que el solo atacante.

En definitiva, fueron confirmados 137 fallecidos, 87 de los cuales ocurrieron en el teatro Bataclan siendo el lugar con mayores fallecidos, y 7 de los fallecidos totales fueron atacantes. Además, hubo 415 heridos, 42 de los cuales gravemente.

El ataque fue luego reivindicado por la organización yihadista autoproclamada como "Estado Islámico" (ISIS o Daesh), actualmente participante de la Guerra en Siria y que abarca también territorios de otros países y enfrentándose a varios Estados, como son Rusia, EEUU y Francia, y recientemente Alemania.

En efecto, el Estado Islámico reivindicó la autoría de dichos ataques a ocho de sus miembros "que llevaban cinturones de explosivos y fusiles de asalto (que) se han dirigido a los lugares elegidos minuciosamente por adelantado en el corazón de la capital francesa", mediante un comunicado difundido en video y en donde señalan como causas del mismo la participación francesa en la Guerra contra el Estado Islámico y "atreverse a insultar al profeta", razón que se conecta también con otro atentado en Francia, contra la revista satírica "Charlie Hebdo". 
Conforme a la Fiscalía francesa, los atacantes del teatro Bataclan fueron Samy Amimour, parisino de 28 años que había combatido en Yemen; Omar Ismail Mostefai, parisino de 29 años; y Foued Mohamed-Aggad, de 23 años y procedente de Estrasburgo, que habrían viajado a Siria en 2013. Los de las cercanías del Estadio de Francia eran Bilal Hadfi, francés residente en Bélgica, de 20 años; Ahmad al-Mohammad, sirio de 25 años que fue refugiado en Grecia; y M. al-Mahmod, edad y nacionalidad desconocida, que también habría sido refugiado en Grecia. Finalmente, los últimos tres que realizaron los demás ataques fueron Brahim Abdeslam, francés residente en Bélgica, de 31 años; Chakib Akrouh, belga de 25 años; y Abdelhamid Abaaoud, belga de 28 años. De todos ellos, fallecieron todos salvo el hermano de Brahim Abdeslam, quien fue recientemente detenido en Bélgica y respecto de quien se solicitó una euro-orden ${ }^{2}$ para su captura, detención y entrega a la jurisdicción francesa, considerando que también tuvo participación en estos ataques.

Toda la información señalada es relevante por cuanto constituyen los hechos y el autor material sobreviviente, pero al mismo tiempo, debemos hacer algunas precisiones en cuanto al contexto y la organización del Estado Islámico.

Al respecto, como contexto, debe precisarse que la Guerra en Siria abarca al menos tres participantes: Por un lado, el Gobierno de Bashar Al Assad apoyado por Rusia; por otro lado, los rebeldes apoyados por EEUU y Francia, entre otros, que buscan establecer un gobierno democrático en oposición al gobierno vigente estimado como autocrático; y finalmente, la organización yihadista autoproclamada como "Estado Islámico", que busca establecer un Estado que consista en un califato árabe conforme al Islam, interpretando a la yihad como una guerra en términos violentos ${ }^{3}$ y por lo tanto, oponiéndose violentamente a los principios y valores occidentales.

En relación a la participación de los demás países se debe señalar que en un comienzo esta participación múltiple estaba provocando bajas importantes tanto en el bando del Gobierno actual de Bashar Al Assad como en los rebeldes, aprovechando dicha situación el Estado Islámico. Sin embargo y en razón de ello, actualmente se ha formado una alianza de no agresión entre todos los participantes salvo el Estado Islámico, concentrando los ataques solo respecto de este último. Luego de ello, de los hechos que han ocurrido se puede desprender que el Estado Islámico ha sufrido importantes bajas en control territorial y miembros en Siria (aunque reporta varios miembros en otros países, principalmente europeos) gracias principalmente a los ataques del gobierno vigente en conjunto con Rusia, que ahora ha retirado parte de sus fuerzas de Siria, así como también ha sufrido importantes bajas en los mandos militares, principalmente gracias al apoyo norteamericano y francés. Se suma a ello la batalla de Mosul actualmente pendiente.

No obstante ello, se puede observar que los ataques de ISIS se están internacionalizando hacia lugares fuera de Siria, como los que se comentan, los que ya han ocurrido o el reciente atentado ocurrido en Bruselas, o el riesgo que se ha indicado respecto a la tenencia de armas nucleares

2 Se debe precisar que una "Euro-Orden" es diferente a un pedido de extradición, pues mientras la extradición consiste en un procedimiento judicial y administrativo, en donde se involucra el criterio político, la euro-orden consiste en un procedimiento judicial en que se solicita al otro Estado la búsqueda, captura, detención y entrega de la persona a la jurisdicción requirente. A su vez, es diferente a la jurisdicción universal como principio, pues éste permite el juicio en cualquier Estado.

3 Cabe hacer la precisión que esta postura radical y violenta del islam no es compartida por otros que profesan dicha religión, habiendo una mayoría moderada que entiende a la yihad como una lucha interna de adoptar los valores, principios y forma de vida que se defiende, y una lucha externa para el convencimiento del otro, pero no en términos violentos.

Número de página no utilizable para citar 
que fue objeto de discusión en la última Cumbre sobre Energía Nuclear. Sobre ello, se han levantado tesis que explicarían estos ataques como técnicas militares del Estado Islámico de mantener la moral de sus fuerzas y debilitar la moral del adversario, que aumentan en número e intensidad a medida que van perdiendo la guerra.

Cabe señalar que ha habido más atentados fuera de los que se comentan, tanto en Francia como en otros países, nombrando por ejemplo aquel ocurrido el 31 de octubre de 2015 en donde el vuelo N$^{\circ} 268$ se estrelló en el Sinaí, Egipto, con más de 200 muertos, afectando mayormente a Rusia.

Finalmente y considerando que estos hechos en concreto se refieren a un país en particular (Francia), precisar que éste ingresa en dicha guerra mediante la llamada "Operación Chammal", dirigiendo ataques aéreos contra objetivos en Irak y Siria desde el 19 de septiembre de 2014, realizando el primer ataque en octubre de 2015, manteniendo su participación hasta la actualidad pero aumentando su intensidad precisamente a partir de estos atentados.

Como se sabe, el ingreso de Francia a dicha guerra habría sido el móvil de estos atentados en contra de la población civil de Francia, cometido por el Estado Islámico, atacando asimismo los principios y valores occidentales, según se desprende del contenido del video en donde dicha organización reivindica la autoría de estos hechos, según mencionamos.

Ahora bien, en lo que respecta a la calificación jurídica de estos hechos, debemos mencionar que evidentemente esos ataques provocaron reacciones a nivel mundial, lo cual resulta lógico y correcto, pero las reacciones se centraron principalmente en calificarlos como terrorismo y de su reacción contra el terrorismo, incluyendo a Rusia entre ellos, además de la defensa de la democracia y los valores occidentales, incluyendo en ello a la OTAN y la UE.

Por otro lado, se destacan las reacciones en Francia, en donde lógicamente se iniciaron las investigaciones y persecuciones penales correspondientes, y además, la declaración de estado de emergencia, el cierre de todas las fronteras francesas y el aumento de la alerta contra el terrorismo, movilizando al ejército francés, pero principalmente la declaración del presidente francés de estimar estos actos como un acto de guerra, intensificando su participación en la Guerra de Siria.

También debe destacarse la reacción de Bélgica de investigación penal en su territorio, considerando su cooperación internacional, habiendo efectivamente detenidos aunque luego liberados por falta de pruebas, aspecto valioso en un Estado de Derecho, en donde comúnmente tras ataques de esta naturaleza se flexibiliza el debido proceso al cambiar el estatuto jurídico aplicable frente a lo que se denominaría como terrorismo, de modo que su conducta es valorable tanto por la cooperación prestada, como por su respeto al Estado de Derecho pese a la gravedad de los delitos cometidos.

Cabe señalar que sería posible hacer un análisis similar, reiterando los criterios planteados pero juzgándolos según cada caso, en los otros ataques perpetrados por ISIS en el marco de la Guerra de Siria, que podrían tener un tratamiento similar a los atentados de París que comentaremos. Tema aparte, sin embargo, sería comparar la Guerra de Siria con la Guerra de Irak, pues se trata de conflictos bélicos diferentes que ameritarían un análisis también diferente. 


\section{Concepto internacional de terrorismo y su naturaleza jurídica}

Considerando que, como se ha dicho, la gran mayoría de los países y la doctrina en general han reaccionado frente a estos hechos calificándolos como "delitos terroristas" con la precisión de Francia que lo calificó como también como un "acto de guerra", y para efectos de sostener la tesis indicada, corresponde precisar primero el concepto del terrorismo a nivel internacional.

$\mathrm{Al}$ respecto, lo primero a señalar es que no existe consenso internacional, habiendo intentos de definición desde el Congreso de Bruselas de 1937 pero sin tener resultados, considerando principalmente el tinte político que esconde dicha calificación, como se explicará.

La definición más moderna, asumida por la Organización de Naciones Unidas (ONU) desde 1994, entiende al terrorismo como "actos criminales, inclusive contra civiles, cometidos con la intención de causar muerte o lesiones graves o de tomar rehenes, con el propósito de provocar un estado de terror en la población en general, en un grupo de personas o en determinada persona, intimidar a una población u obligar a un gobierno o a una organización internacional a realizar un acto, o a abstenerse de realizarlo". ${ }^{4}$

Sin embargo, dicha definición tiene fuerza vinculante discutida y tiene numerosas deficiencias, comenzando con la amplitud de la figura que puede llevar a una vulneración del principio de reserva legal considerando principalmente la expresión amplia de "actos criminales", sin perjuicio de que dicha expresión pueda interpretarse de forma restrictiva mediante la intención exigida de causar muerte, lesiones graves o toma de rehenes, en el sentido de precisar, por vía de interpretación restrictiva, que se trataría de delitos contra las personas.

Además, tiene más deficiencias en cuanto al principio de lesividad, pues si bien exige la intención de provocar dichos resultados, no precisa si se exige o no el resultado o si pudiera ser figura de peligro. Esto sin perjuicio de una postura restrictiva que señale que al referirse a "actos criminales" implique una expresión técnica que exige también el resultado, postura discutible por cuanto se refiere a actos criminales pero no al homicidio, las lesiones o el secuestro, por ejemplo, expresiones las cuales efectivamente conllevarían los elementos que derivan de la definición técnica aludida, lo que no ocurre con "actos criminales" ni con "la intención de causar muerte, lesiones, o la toma de rehenes".

Asimismo, equivoca este concepto en materia de medios empleados, pues no basta con la intención de provocar temor sino que también debiese exigir que el medio empleado tenga una peligrosidad real que justifique dicho temor, independiente asimismo del efecto de la publicidad o del periodismo en el surgimiento de dicho temor. En el mismo sentido, debe excluirse de la definición el terror ocasionado a alguna persona determinada, pues por esencia, el delito terrorista debería exigir intimidación masiva.

4 Definición preliminar de terrorismo dada por la Organización de Naciones Unidas (ONU, 1994), explicada por Daniela Quiroz Becerra, Master en Justicia Criminal de la Universidad Carlos III de Madrid, capacitación realizada en la Defensoría Penal Pública, Diciembre de 2015.

Número de página no utilizable para citar 
Por otro lado, debe precisarse en materia de intención que el delito terrorista tendría que llevar una doble intencionalidad: En primer lugar, la del acto criminal concreto (homicidio, lesiones, etcétera) y en segundo lugar, la intención general de provocar terror, pero excluir a su vez el propósito de obligar a un Gobierno u organización internacional a realizar un acto o abstenerse de hacerlo, pues ello asimila sobremanera el delito terrorista con el delito político o de Seguridad Interior del Estado, aspecto que es, en definitiva, el que permitió que personalidades como Nelson Mandela sean juzgadas por delitos terroristas, y a su vez, resulta irrelevante y confuso pues iguala el "motivo" con la "intención", siendo el primero irrelevante para el segundo, y también para el delito en sí, salvo en lo que respecta a la determinación de la pena.

Así lo ha sostenido también Kai Ambos, que al respecto aclara que la intencionalidad exigida es doble, de tipo general y especial, de modo que "por un lado, el autor debe actuar con intención general respecto al acto criminal en cuestión, por ejemplo, homicidio, lesiones, toma de rehenes. Por el otro lado, se requiere una intención especial de diseminar miedo o coaccionar a una autoridad", 5 pero al mismo tiempo, "la intención especial a menudo derivaría de un propósito político o ideológico subyacente"6 y en dicho sentido, "los motivos no deberían jugar ningún papel en el delito" pues "el posible motivo, a saber, la razón por la cual un autor realiza cierto acto, es irrelevante para su intención (tesis de la irrelevancia)", 8 de modo que "un motivo solamente puede ser tomado en consideración en la etapa de la determinación concreta de la pena como un factor atenuante o agravante".?

Finalmente, se le puede criticar a este concepto la omisión de la exigencia de la organización como sujeto activo, o como elemento de imputabilidad mixta conforme lo desarrollado por Kai Ambos, ${ }^{10} \mathrm{o}$ al menos como condición objetiva de punibilidad. Si bien esta omisión podría permitir incluir el llamado "terrorismo individual", excluiría inmediatamente la posibilidad de tratarlo como delito internacional al carecer de la imputabilidad mixta.

Observando todas esas críticas, analicemos un segundo intento de definición, que es uno asumido por la doctrina a partir de diversas fuentes normativas, como son la Resolución $\mathrm{N}^{\circ} 1.566 / 2004$ del Consejo de Seguridad de la ONU, la Decisión Marco sobre Lucha contra el Terrorismo de la Unión Europea (UE) y el Proyecto de Convención Integral sobre Terrorismo. Además de otras convenciones que sancionan figuras específicas, como son la Convención contra Atentados con Bombas, la Convención contra la Toma de Rehenes, o la Convención contra el Apoderamiento de Naves o Aeronaves.

5 Kai Ambos, Derecho Penal y Procesal Penal Internacional y Europeo (Santiago de Chile; Legal Publishing, 2013), 167. Texto original: "Judicial Creativity at the Special Tribunal for Lebanon: Is there a Crime of Terrorism under International Law?", Leiden Journal of International Law (2011). Traducido por Ezequiel Malarino, "Creatividad Judicial en el Tribunal Especial para el Líbano: ¿Es el Terrorismo un Crimen Internacional?”.

6 Ambos, Derecho Penaly Procesal Penal Internacional y Europeo, 168.

Ambos, Derecho Penal y Procesal Penal Internacional y Europeo, 168.

Ambos, Derecho Penal y Procesal Penal Internacional y Europeo, 168.

Ambos, Derecho Penaly Procesal Penal Internacional y Europeo, 168.

10 Vid. Kai Ambos, “¿Castigo sin Soberano? La Cuestión del Ius Puniendi en Derecho Penal Internacional. Una primera contribución hacia una consistente teoría de Derecho Penal Internacional”, en: Derecho Penal y Procesal Penal Internacionaly Europeo (Santiago de Chile; Legal Publishing, 2013), 7-43. Publicado originalmente en Oxford Journal of Legal Studies, 33 N²(2013).Ttraducido por Ezequiel Malarino; y Kai Ambos, "Sobre la Organización en el Dominio de Organización”, en Derecho Penal y Procesal Penal Internacional y Europeo (Santiago de Chile; Legal Publishing, 2013), 63-84. Publicado originalmente en InDret Penal 3 (2011).

Número de página no utilizable para citar 
A partir de dichas fuentes normativas la doctrina, principalmente afirmada por Kai Ambos, ${ }^{11}$ ha definido al delito terrorista como un "acto criminal que ilícita e intencionalmente, y por cualquier medio, cause daño a la vida, libertad, integridad (gravemente) o propiedad (sea pública o privada), incluida la amenaza concreta (grave y creíble), o la tentativa de ello, de carácter grave que amenace a la estabilidad de la sociedad o de un Estado, cometido con la intención de causar terror", precisando que se trata de una intención especial general del acto concreto y de causar terror, pero no una intención especial especial del acto concreto, causar temor, y conseguir la acción o abstención de la autoridad, considerando lo antes explicado, es decir, que conlleva un tinte político y que el motivo es irrelevante para el tipo penal, no es lo mismo que la intención, y su relevancia puede limitarse solo a la determinación de la pena concreta.

A su vez, se agrega que como elemento complementario para efectos de jurisdicción para ser transnacional, debe involucrar al menos a dos Estados, sea por el territorio que resulta afectado o sea por los sujetos que se encuentran involucrados. ${ }^{12}$

Ahora bien, si bien esta definición doctrinaria supera algunas críticas o deficiencias del concepto antes analizado, como es la afectación al principio de lesividad y la precisión de una doble intencionalidad especial y general excluyendo la intencionalidad política, mantiene otras deficiencias, como es la amplitud de la figura pudiendo afectar el principio de reserva legal, como ya se explicó, en donde incluso incluye expresamente delitos contra la propiedad, continúa el defecto de omitir la exigencia de la organización, los medios empleados y la intimidación masiva.

No obstante este análisis, debemos resaltar que actualmente no hay concepto internacional de terrorismo, como lo concluye también el autor ya citado, ${ }^{13}$ sino que solo un concepto dado por la ONU que padece de muchas deficiencias, y otro concepto doctrinario que supera algunas deficiencias pero mantiene otras, y que además, en ningún caso resulta vinculante y mucho menos desde una perspectiva jurídico-penal.

Lo cierto es, por tanto, que al no haber definición internacional del terrorismo, se acude a conceptos nacionales, en donde un caso sumamente relevante desde la perspectiva internacional y del Derecho francés por su similitud, es el adoptado por el Líbano, en el Art. 314 de su Código Penal $^{14}$ y precisado por la Corte Especial para el Líbano.

En este caso, se define al terrorismo como "cualquier acto a través de medios que son, per se, propensos a crear un peligro público, con la intención de causar un impacto considerable de terror sobre la población o parte importante de ella", ${ }^{14}$ en donde si bien mantiene la doble intencionalidad excluyendo el elemento político o el religioso, y supera los defectos en cuanto a la intimidación masiva y la peligrosidad real del medio empleado que justifique el temor provocado, continúa la amplitud de la figura e incluso retrocede, pues no solo usa similar expresión amplia sino que ni si quiera menciona ciertos delitos contra las personas o contra la propiedad que permitan una interpretación restrictiva, como asimismo retrocede al no exigir el resultado lesivo, y continúa el problema de la exigencia de la organización antes explicada.

\footnotetext{
Vid. Ambos, Derecho Penal y Procesal Penal Internacional y Europeo, 139-169.

Ambos, Derecho Penal y Procesal Penal Internacional y Europeo, 139-169.

Ambos, Derecho Penaly Procesal Penal Internacionaly Europeo, 169.

Código Penal del Líbano, Art. 314.
}

Número de página no utilizable para citar 
Asimismo, debemos destacar que no solo presentan estos problemas a nivel conceptual las legislaciones nacionales, sino que también, muchas veces, se agregan defectos en cuanto al respeto al debido proceso. En efecto, como señala Sebastián Dozo Moreno explicando la tesis de Günter Jakobs, ${ }^{15}$ habría dos tipos de sujetos penales, los comunes a quienes se les aplica una política criminal del ciudadano, y los terroristas, respecto de quienes se reacciona con una política criminal del enemigo. Con esta reacción, sostenemos, las legislaciones nacionales suelen afectar su propio Estado de Derecho, Social y Democrático, perdiendo la lucha filosófica frente a quienes serían los terroristas.

Por otro lado, frente a esta reacción legislativa, en muchos países el Poder Judicial exige mayor estándar probatorio considerando la gravedad de la conducta, principalmente por vía probatoria del elemento subjetivo, excluyendo cualquier posibilidad de prueba indiciaria y por tanto, provocando una división entre la reacción legislativa y la judicial. Sin perjuicio de otros países en donde el Poder Judicial también hace esa diferencia, vulnerando así el debido proceso.

Lo primero ocurre, por ejemplo, en el caso chileno, respecto del cual se podría realizar un mayor análisis incluyendo el debido proceso, y lo segundo ocurre en el caso español, pero por razones de interés de este trabajo se omitirán dichos análisis para destacar dos ideas que hemos venido desarrollando: En primer lugar, la ausencia de concepto de terrorismo a nivel internacional, y en segundo lugar, el acudir a conceptos nacionales al respecto, en donde muchas veces se confunde con los delitos políticos y se vulneran las garantías de un debido proceso, derecho reconocido y garantizado internacionalmente.

Habiendo destacado esas ideas, detengámonos brevemente en la naturaleza jurídica del terrorismo, es decir, respondamos a la pregunta de si se trata de un delito internacional, transnacional o nacional.

Sobre este punto, sostenemos que el terrorismo, aun si existiere una definición internacional clara y completa al respecto, se trata de un delito nacional o transnacional, dependiendo de si hay o no dos o más Estados involucrados, sea por territorio o sea por sujetos (reiterando la exigencia a nivel de jurisdicción aportada por Kai Ambos), ${ }^{16}$ y esto por varios motivos desarrollados algunos de ellos por dicho autor, a saber:

En primer lugar, pues desde una perspectiva de Derecho Positivo, los tratados internacionales sobre el terrorismo se refieren a una norma prohibitiva respecto de la conducta, cuya infracción es grave, pero no como norma sancionatoria de tipo penal internacional, sino que estos tratados obligan al Estado a prevenir y sancionar dichas conductas, siendo su destinatario el Estado más no la persona natural individual que comete el delito terrorista. ${ }^{17}$

En segundo lugar, y siguiendo la misma lógica expresada como primer argumento, agregamos que la imputabilidad en dichos delitos se traduce en una imputabilidad individual, pero no mixta

\footnotetext{
15 Vid. Sebastián Dozo Moreno, "El Enemigo tiene menos derechos”, dice Günter Jakobs”, Diario La Nación, 26 de julio de 2006.

16 Vid. Ambos, Derecho Penaly Procesal Penal Internacionaly Europeo", 139-169.

17 Ambos, Derecho Penaly Procesal Penal Internacionaly Europeo", 139-169.
}

Número de página no utilizable para citar 
como es la exigencia en Derecho Penal Internacional, apartándose así de la exigencia del dominio de organización de Roxin y de la imputabilidad mixta de Kai Ambos. ${ }^{18}$

Finalmente, agregamos que la norma consuetudinaria que sancionaría al delito terrorista es insuficiente para materia penal, más aun respecto de un crimen penal internacional, pues en dichas materias rige el principio de reserva legal, necesitando el texto escrito y positivo, pues si bien es Derecho Internacional, tiene una naturaleza penal que exige el cumplimiento de estos principios, sostenidos al mismo tiempo en el Estatuto de Roma.

Al respecto, debemos precisar que si bien el Estatuto de Roma establece de forma amplia las fuentes normativas a aplicar, ${ }^{19}$ lo hace para efectos de interpretación de la ley, más no para efectos de tipicidad de la conducta, pues ahí se exige la tipicidad derivada del principio de nullum crimen sine lege, también establecido expresamente en el Estatuto, ${ }^{20}$ no bastando por tanto, la costumbre jurídica internacional aun cuando sea reconocida como fuente en el Art. 21 al remitirse al Art. 38 del Estatuto de la Corte Internacional de Justicia. ${ }^{21}$ De esta forma, la costumbre importa para efectos de interpretación de los tipos penales ya tipificados, pero no para tipificar un crimen nuevo y autónomo diferente a los ya tipificados por el Estatuto de Roma. Se trata, por tanto, de un salto cualitativo y positivo que no se satisface con la sola norma consuetudinaria.

De esta forma, sostenemos que el delito terrorista tiene una naturaleza nacional o transnacional según si involucra o no a dos o más Estados (por territorio o por sujetos, según lo ya explicado), más no a un crimen de Derecho Penal Internacional, y por tanto, el estatuto jurídico a aplicar continúa siendo la legislación nacional, que a su vez, muchas veces confunde el delito político con el delito terrorista y altera las normas del debido proceso afectando los estándares mínimos de aquél.

Por lo tanto, a modo de resumen en el análisis del delito terrorista como delito transnacional o nacional, debemos reiterar que dicha calificación tiene desventajas tanto a nivel normativo como a nivel de persecución penal y debido proceso para el imputado.

En efecto, desde la perspectiva legislativa, el problema del delito terrorista es la confusión con los delitos políticos que varían de Estado a Estado, con una tipicidad flexible que atenta contra el principio de reserva legal, y con muchas deficiencias normativas. Al mismo tiempo, desde la perspectiva de persecución penal y respeto al debido proceso, el Derecho Penal Internacional da, efectivamente, mayores razones para ser utilizado.

Sostenemos lo anterior por cuanto a diferencia de los delitos terroristas, los crímenes del Derecho Penal Internacional hacen competente a la Corte Penal Internacional y son de jurisdicción internacional, habiendo también un respeto al Derecho y cuyo procedimiento respeta el debido proceso, excluyendo, por ejemplo, la pena de muerte, o permitiendo una completa contradictoriedad durante el procedimiento, una etapa de admisibilidad, otra de juicio e incluso la apelación.

\footnotetext{
Vid. Ambos, Derecho Penal y Procesal Penal Internacionaly Europeo”, 7-43 y 63-84.

9 Estatuto de Roma de 1998, Art. 21.

Estatuto de Roma de 1998, Art. 22.

21 Estatuto de Roma de 1998, Art. 21; Estatuto de la Corte Internacional de Justicia, Art. 38 letra b).
}

Número de página no utilizable para citar 
Por su parte, el Derecho Penal Internacional excluye la posibilidad de prescripción, amnistía, indultos e inmunidades diplomáticas, tanto por razones positivas de un deber de persecución por parte del Estado, como también por cuanto esas son instituciones que limitan el poder punitivo del Estado, no siendo razonable que el mismo Estado, que muchas veces es el elemento de la imputabilidad mixta de estos crímenes, limite la persecución a favor de sí mismo.22

Desde la perspectiva del régimen jurídico, también hay diferentes normas en cuanto al principio de reserva legal, respecto de la faz subjetiva de los tipos penales, la participación, y las circunstancias eximentes y modificatorias de responsabilidad penal, permitiendo por tanto que no haya impunidad.

Pero por otro lado, si bien impide la impunidad, garantiza que el juicio sea con pleno respeto al debido proceso, con los trámites ya indicados de etapa de admisibilidad, de juicio y de apelación, al mismo tiempo de garantizar el ejercicio de los derechos del imputado, garantizando la plena contradictoriedad durante el procedimiento, y existiendo penas acorde con los derechos humanos, pues excluye la posibilidad de la pena de muerte, procurando, asimismo, penas proporcionales pero no inhumanas.

Considerando todo lo recién expuesto, corresponde ahora detenerse en un siguiente apartado para buscar responder a la pregunta de si hay otra reacción jurídica posible, no referida al delito terrorista, que inserte estos hechos en la calificación de crimen de Derecho Penal Internacional.

22 Vid. Ricardo Luis Lorenzetti, y Alfredo Jorge Kraut, Derechos Humanos: Justicia y Reparación. La experiencia de los juicios en la Argentina. Crimenes de Lesa Humanidad (Buenos Aires, Argentina; Sudamericana S.A., 2011). Particularmente, voto de Jueces Zaffaroni y Nolasco, en caso Arancibia Clavel; Voto de Jueces Petrachi, Boggiano y Maqueda, Lorenzetti, y Zaffaroni y Nolasco, en caso Simón; Voto de Jueces Belluscio y Levene en caso Leyes de Menem; Sentencia caso Mazzeo; Sentencia en caso Barrios Altos y Rodríguez, Corte Interamericana de DDHH; y Sentencia en caso Almonacid-Chile, Corte Interamericana de DDHH. 


\section{Otra alternativa: crímenes de guerra ${ }^{23}$}

Como sostuvimos, estos hechos no deben ser calificados como delitos terroristas, pues como delito transnacional o nacional implicaría la aplicación de legislación doméstica que muchas veces confunde el delito político con el delito terrorista, otras veces vulnera el debido proceso, y en cualquier caso limita la jurisdicción, teniendo más desventajas que la postura que lo califica como crimen de Derecho Penal Internacional (que garantiza sanción pero con respeto al debido proceso, estableciendo además sanciones proporcionales pero no inhumanas).

Concretamente, sostenemos que estos hechos pueden ser calificados como crímenes de guerra, conforme al Estatuto de Roma de 1998 y tomando por base los mismos hechos ya relatados, destacando también el contexto de los mismos como asimismo la calificación como "acto de guerra" que realizó el Gobierno Francés.

Conforme al Art. 8 del Estatuto de Roma de 1998, complementado con los Elementos de los Crímenes ${ }^{24}$, los crímenes de guerra requieren de un contexto bélico, sea de carácter interno o internacional, conforme con los Convenios de Ginebra de 1949, pero sin exigir que el sujeto activo haya hecho una evaluación jurídica sobre si el conflicto bélico califica como lo exigen las convenciones antes dichas, sino solamente que haya conocido los hechos que califican al contexto de esa forma.

Asimismo, tampoco se exige que exista un plan o política al respecto, o como parte de comisión a gran escala de tales crímenes, pues esa expresión utilizada en el Art. 8 solo se refiere a que tendrá "especial" competencia en dichos casos, y por lo tanto, existiría competencia también sobre casos que no cumplan con tales características.

Por otro lado, no se distingue en la calidad del sujeto pasivo, pudiendo ser población civil o militar, miembros de misiones humanitarias de las Naciones Unidas, o aquellos que tengan protección internacional según los mismos Convenios de Ginebra. No obstante, acá tampoco se exige la evaluación en Derecho al respecto por parte del sujeto activo, bastando también con el

23 Para una revisión sobre jurisprudencia de la Corte Penal Internacional y un enfoque práctico, incluyendo crímenes de guerra y en particular el reclutamiento de menores, vid. Claudia Cárdenas Aravena y Karinna Fernández Neira, La Corte Penal Internacionaly sus primeros diez años: Un enfoque práctico (Santiago de Chile; Legal Publishing, 2013), particularmente pp. 61-73, El Crimen de Guerra de Reclutar, Alistar y Utilizar a Menores de 15 años para participar activamente en las hostilidades según la Corte Penal Internacional, de María José Chible Villadangos.

Para una revisión histórica sobre juicios relacionados a crímenes de guerra, además del primer texto antes citado, vid. Kevin Jon Heller and Jerry Simpson, The Hidden Histories of W ar Crimes Trials (UK, University of Oxford); Theodor Meron Reflections on the Prosecution of War Crimes by International Tribunals (The American Journal of International Law, Vol. 100, No. 3 (Jul., 2006), pp. 551-579, American Society of International Law, http://www.jstor.org/stable/4091370 [consulta: 05.may.2017]; y Final Report to the United States Congress, April 2007, Nazi W ar Crimes and Japanese Imperial Government Records. Interagency Working Group.

Para un análisis de la formación de los crímenes de guerra en los Elementos de los Crímenes, vid. Knut Dormann, War Crimes under the Rome Statute of the International Criminal Court, with a special focus on the Negotiations on the Elements of Crimes (Netherlands, Max Planck UNYB 7, 2003).

Para una comparación entre crímenes de guerra conforme al Estatuto de Roma y las Convenciones de Ginebra, vid. International Commettee of the Red Cross, War Crimes under the Rome Statute of the International Criminal Court and their source in International Humanitarian Law. Comparative Table.

24 Estatuto de Roma de 1998, Art. 8; y Elementos de los Crímenes. 
conocimiento de los hechos que hagan al sujeto víctima como protegido internacionalmente por los Convenios de Ginebra.

Más allá de estos puntos previos que dan cuenta de cierta amplitud en la tipicidad de estos crímenes, corresponde precisar que esas discusiones no se darían en relación a los hechos que comentamos, salvo el aspecto en cuanto al contexto, que tomando por base lo dicho por las Convenciones de Ginebra, constituye un conflicto bélico de carácter internacional.

En efecto, es posible concluir lo anterior a partir del análisis de los Arts. 2 y 3 comunes a las cuatro Convenciones de Ginebra, y los Arts. 1 de los dos primeros Protocolos Adicionales, ${ }^{25}$ por cuanto de esas disposiciones se desprende la diferencia entre el conflicto interno y el internacional.

Así, constituye conflicto bélico internacional la "guerra declarada o de cualquier otro conflicto armado que surja entre dos o varias Altas Partes Contratantes, aunque una de ellas no haya reconocido el estado de guerra", conforme al Art. 2, común a las cuatro Convenciones. ${ }^{26}$ En estos casos se aplican las cuatro Convenciones de Ginebra y el Protocolo Adicional Nº1 y 3.

Así también se aplicará “en todos los casos de ocupación total o parcial del territorio de una Alta Parte Contratante, aunque tal ocupación no encuentre resistencia militar" $27 \mathrm{y}$, en caso de que una las partes en conflicto no es parte del convenio, "las Potencias que son Partes en el mismo estarán, sin embargo, obligadas por él en sus relaciones recíprocas. Estarán, además, obligadas por el Convenio con respecto a dicha Potencia, si ésta acepta y aplica sus disposiciones" 28.

Por otro lado, conforme al Art. 1 del Protocolo N² que complementa el Art. 3, común a los cuatro Convenios de Ginebra, constituyen conflictos internos "todos los conflictos armados que no estén cubiertos por el artículo 1 del Protocolo adicional a los Convenios de Ginebra (se refieren a los conflictos internacionales del Art. 2 común a los Convenios de Ginebra)... y que se desarrollen en el territorio de una Alta Parte contratante entre sus fuerzas armadas y fuerzas armadas disidentes o grupos armados organizados que, bajo la dirección de un mando responsable, ejerzan sobre una parte de dicho territorio un control tal que les permita realizar operaciones militares sostenidas y concertadas y aplicar el presente Protocolo. / 2. El presente Protocolo no se aplicará a las situaciones de tensiones internas y de disturbios interiores, tales como los motines, los actos esporádicos y aislados de violencia y otros actos análogos, que no son conflictos armados". ${ }^{29}$

Por lo tanto, es conflicto internacional aquella guerra (conflicto armado), sea o no declarada y/o reconocida, entre dos o más Estados, o aquella ocupación total o parcial del territorio de un Estado aun sin resistencia militar, mientras que es conflicto interno todo otro conflicto bélico en el territorio de un Estado entre sus FFAA y FFAA disidentes o grupos armados organizados que, bajo la dirección de un mando responsable, ejerzan sobre una parte de dicho territorio un

25 Convenciones de Ginebra de 1949, Arts. 2 y 3 comunes; Primer y Segundo Protocolos Adicionales a las Convenciones de Ginebra, Art. 1.

26 Convenciones de Ginebra de 1949, Art. 2 común, inciso $1^{\circ}$.

27 Convenciones de Ginebra de 1949, Art. 2 común, inciso $2^{\circ}$.

28 Convenciones de Ginebra de 1949, Art. 2 común, inciso $3^{\circ}$.

29 Protocolo Adicional a las Convenciones de Ginebra, N², Art. 1, en relación con Convenciones de Ginebra de 1949, Arts. 2 y 3 común. 
control tal que les permita realizar operaciones militares sostenidas y concertadas, excluyendo de ello las tensiones internas y disturbios interiores.

En el caso de la Guerra de Siria, si bien pareciera ser de carácter interno pues, primero, se trata de un conflicto armado dentro de su territorio entre las FFAA de Bashar Al Assad y el Estado Islámico, no concurriendo la excepción establecida en la misma disposición de ser una mera tensión o disturbio interno, o actos aislados, y segundo, no se trataría de un conflicto entre Estados sino que entre varios Estados y un grupo en particular al interior de un Estado, es más bien de carácter internacional, pues tiene la participación de más Estados y, precisamente, en este caso que se comenta la población afectada no fue de Siria sino que de Francia, sin importar si son dos Estados los que están en conflicto, bastando la existencia de una organización, y por otro lado, también es de carácter internacional pues el control territorial que tiene ISIS excede las fronteras sirias.

Esta calificación es relevante por el tipo penal a aplicar para estos casos, pues los crímenes de guerra en el Estatuto de Roma distinguen entre conflictos internacionales e internos, además de la figura general, ${ }^{30}$ pero en cualquier caso, al ser conflicto bélico, se aplican dichas convenciones. Sin perjuicio de ello, como ya explicamos, considerando la participación de Estados, las víctimas que sobrepasan las de un Estado, y los territorios controlados por el grupo del Estado Islámico, constituirían un conflicto internacional, no un conflicto interno.

Cabe agregar, en todo caso, que en opinión de James G. Stewart, ex Fiscal del Tribunal para la ex Yugoslavia, distinguir entre un conflicto internacional y uno no internacional resulta inútil desde la perspectiva persecutoria, pues en cualquier caso los actos mencionados son considerados crímenes internacionales, y además, resulta teóricamente complejo, ya sea asumiendo el criterio mixto de distinguir cada caso según criterio temporal y espacial si una conducta se enmarca en conflicto interno o internacional (resulta complejo e impracticable), o ya sea asumiendo un criterio global considerando la participación de otros Estados con el problema de que podría no ajustarse dicha calificación a la realidad, según su parecer. ${ }^{31}$

Ahora bien, continuando con este análisis, el Art. 8 del Estatuto de Roma de 1998 complementado con los Elementos de los Crímenes, no exige que el sujeto activo haya evaluado jurídicamente sobre si el conflicto es interno o internacional, bastando que conozca los hechos que lo califican como tal, elemento que es fácilmente acreditable.

Como sostuvimos, el Art. 8 tampoco exige un plan o política al respecto como parte de comisión a gran escala de tales crímenes, siendo solo un caso en que la Corte Penal Internacional tendrá "especialmente" competencia, sino que basta con su comisión. No obstante, en este caso es probable que estos atentados obedezcan efectivamente a un plan o política o comisión a gran escala de estos crímenes, considerando la misma reivindicación que el Estado Islámico hace de estos atentados.

30 Estatuto de Roma de 1998, Art. 8.

31 Stewart, James G, "How Would War Crimes Prosecutors Classify the Syrian Conflict(s)?” Blog International Criminal Justice. International Humanitarian Law, 20 de octubre del2016, http://jamesgstewart.com/how-would-war-crimes-prosecutorsclassify-the-syrian-conflicts/ [consulta: 05.may.2017].

Número de página no utilizable para citar 
Finalmente, es claro que las víctimas en este caso corresponden a la población civil, siendo actuaciones prohibidas por el Derecho sobre la Guerra y sin exigir la evaluación jurídica de los hechores sobre el sujeto pasivo, bastando el conocimiento de los hechos que fundan esta calidad, es decir, que es un atentado a la capital francesa sin discriminar tipo de víctimas, cuestión que también es fácilmente acreditable observando la relación de los hechos.

Por tanto, en primer lugar, se trata de conflicto internacional, y en segundo lugar, se dan los elementos exigidos por el encabezado del Art. 8 del Estatuto de Roma, es decir, las exigencias generales de los tipos penales de crímenes de guerra, que es el contexto y el tipo de víctima, sin exigir al respecto la evaluación jurídica, y asimismo, sin que necesariamente deba existir un plan o política o comisión a gran escala, que aun así es probable que se acredite aquello en este caso.

Continuando con este análisis, concretamente, los atentados en París califican dentro de la letra b) del Art. 8.2 del Estatuto de Roma, complementado con los Elementos de los Crímenes, que se refiere a "otras violaciones graves de las leyes y usos aplicables en los conflictos armados internacionales dentro del marco del derecho internacional", y concretamente, en relación a ataques contra la población civil, el "dirigir intencionalmente ataques contra la población civil en cuanto tal o contra civiles que no participen directamente en las hostilidades". ${ }^{32}$

Por lo demás, también es posible aclarar que califica también como la figura general de los crímenes de guerra, es decir, aquellas establecidas en la letra a) del Art. 8.2, es decir, "infracciones graves de los Convenios de Ginebra de 1949 mediante actos atentatorios contra las personas o bienes protegidos por dichos convenios", y concretamente, el "matar intencionalmente" (homicidio) y el "capturar, detener o mantener en calidad de rehenes a una o más personas, amenazándolas con su muerte, herirlo o mantenerlo en dicho situación” (secuestro). ${ }^{33}$

De esta forma y a modo de síntesis, constituye un conflicto internacional, concurren los elementos comunes de los crímenes de guerra (contexto, tipo de víctima, plan o política o comisión a gran escala, sin exigir evaluación jurídica del hechor) y concretamente, califican dentro de la figura de ataque a la población civil en conflicto internacional conforme a la letra b) del Art. 8.2, o bien, como ataque a la población civil como figura general conforme a la letra a) del Art. 8.2.

Con lo anterior, como hemos venido sosteniendo, se le da competencia a la Corte Penal Internacional y se activa la jurisdicción universal como teoría aplicable, dando paso a los procedimientos regulados en dicha normativa, respetando el debido proceso con varias etapas, contradictoriedad y con penas proporcionales pero no inhumanas, y al mismo tiempo, excluyendo la posibilidad de prescripción, amnistía, indultos e inmunidades diplomáticas, por las razones que ya hemos expuesto. Asimismo, se aplica el régimen jurídico establecido en el Estatuto de Roma también en cuanto al principio de reserva legal, respecto de la faz subjetiva de los tipos penales, la participación, y las circunstancias eximentes y modificatorias de responsabilidad penal, permitiendo por tanto que no haya impunidad.

32 Estatuto de Roma de 1998, Art. 8.2 letra b), y Elementos de los Crímenes.

33 Estatuto de Roma de 1998, Art. 8.2 letra a), y Elementos de los Crímenes. 


\section{Perspectiva procesal penal internacional}

Ahora bien, para finalizar corresponde realizar breves comentarios desde la perspectiva procesal, pues es lo que permite la viabilidad real de hacer efectiva esta tesis. En este sentido, debemos destacar cuatro aspectos, a saber: El principio de complementariedad, el orden de prelación de jurisdicciones, los criterios de selección de la Fiscalía de la Corte Penal Internacional, y el examen de admisibilidad por parte de la Corte.

Desde la perspectiva del principio de complementariedad, éste consiste, a modo de síntesis, en aquel principio que informa el proceso penal internacional en el sentido del deber de consulta al Estado respectivo ${ }^{34}$ de si tales atentados son juzgados por sus tribunales o por la Corte Penal Internacional, salvo en el caso que el Estado pretenda juzgar para evadir la justicia, no quiera juzgar o simplemente no pueda.

Surge la pregunta en este sentido de si se podría aplicar igualmente la Corte Penal Internacional en el caso de que, aun pudiendo y queriendo juzgar efectivamente los hechos, sin buscar evadir la justicia, no se dan las garantías necesarias del debido proceso, similar en este sentido a la excepción del reconocimiento de las sentencias penales extranjeras que establece, en nuestro Derecho, el Art. 13 del Código Procesal Penal. ${ }^{35}$ Como se desarrollará, este punto ingresa en el análisis de capacidad y disposición del Estado para juzgar.

Sin perjuicio de esta segunda pregunta, que amerita un examen sobre el debido proceso en casos de delitos terroristas, si se juzgara en esa calidad, bajo el Derecho Procesal Penal francés, por realismo político, basta con precisar que debiese ser consultado el Gobierno Francés al respecto, respetando la hipótesis central del principio de complementariedad sin entrar a distinguir, por ahora, si el Derecho Procesal Penal francés afecta o no el debido proceso en casos de delitos terroristas.

Lo anterior es importante porque, conforme a este mismo principio de complementariedad, acompañado con el principio de cooperación internacional y el control de convencionalidad desde la perspectiva del Derecho Interno, se establece una especie de orden de prelación de jurisdicciones en estos casos, privilegiando en primer lugar la jurisdicción nacional del Estado respectivo, luego la aplicación de la jurisdicción universal, luego si existiere algún Tribunal Penal Internacional Especial, y finalmente la Corte Penal Internacional.

Suponiendo que conforme lo ya dicho, Francia decide que estos hechos sean juzgados por la Corte Penal Internacional y no por sus propios tribunales, dando aplicación al Estatuto de Roma, que es la ventaja de esta tesis, y al mismo tiempo el Gobierno Sirio acepta esta jurisdicción para los miembros del Estado Islámico, que no son miembros del Gobierno sirio, y no habiendo tampoco Tribunal Penal Internacional Especial creado al efecto, se activaría finalmente la jurisdicción universal y la Corte Penal Internacional.

\footnotetext{
34 Al señalar "Estado respectivo" se alude a aquel que tiene la jurisdicción sobre tales imputados por tales hechos, sea aplicando cualquiera de las teorías de jurisdicción, como es la jurisdicción territorial, nacional o protectiva pasiva, entre otras, sin perjuicio de las discusiones doctrinarias y jurisprudenciales al respecto. .

35 Código Procesal Penal de Chile, Art. 13.
}

Número de página no utilizable para citar 
El tercer y cuarto comentario se refiere al examen preliminar que realiza la Fiscalía para dar inicio a un proceso penal internacional, y el examen de admisibilidad que realiza la misma Corte Penal Internacional.

En este sentido, corresponde precisar que conforme a las normas que rigen a la Fiscalía de la Corte Penal Internacional, ${ }^{36}$ el examen preliminar que aquel órgano realiza se refiere a cinco aspectos, a saber:

a) En primer lugar, identificar la región correspondiente, que en este caso sería Francia y Siria;

b) En segundo lugar, observar el tipo de crímenes y seleccionar los hechos más importantes, que sin perjuicio de otros hechos, por lo pronto y para efectos de esta tesis, bastaría la selección de estos hechos que comentamos, es decir, los atentados ocurridos en París el 13 de noviembre de 2015;

c) En tercer lugar, calificar la gravedad de los mismos y el número y tipo de víctimas, que en estos hechos la gravedad estaría dada por el ataque indiscriminado a la población civil, con más de 100 muertos y más de 400 heridos, sin distinguir si las víctimas son mujeres, niños, etcétera;

d) En cuarto lugar, observar el nivel de impacto internacional, que en este caso queda comprobado por las reacciones de la comunidad internacional en general, tanto de organismos internacionales como de los Estados; y

e) En quinto lugar, la viabilidad de identificar y procesar a los mayores responsables, que en este caso sería el aspecto de mayor dificultad para superar e iniciar un proceso penal internacional, pues requiere identificar a los mayores responsables, no bastando el ejecutor directo (Abdeslam) que se encuentra detenido en Francia, sino que también los mandos superiores del Estado Islámico, y asimismo, sortear la dificultad en procesar a estas personas, existiendo aun la guerra, siendo otra alternativa optar por esta tesis pero luego de terminado el conflicto bélico, es decir, un cambio en la oportunidad.

Finalmente, desde la perspectiva del examen de admisibilidad que realiza la Corte Penal Internacional, particularmente, durante la etapa escrita de investigación y admisibilidad ante la Sala de Cuestiones Preliminares de la CPI, la regla general es que estos procesos sean declarados admisibles, salvo en los casos expresados en el Estatuto de Roma y en las Reglas de Procedimiento y Prueba. ${ }^{37}$

En concreto, la Sala de Cuestiones Preliminares declarará inadmisible solo en tres casos, a saber:

a) Si la causa ya se está conociendo o ya fue juzgada por el Estado que tenga jurisdicción sobre aquel, salvo si no puede o no quiere hacerlo, es decir, en este caso sería Francia por territorio en donde ocurrió el hecho y por la nacionalidad de las víctimas, y también por nacionalidad de victimarios (Abdeslam es ciudadano francés) aunque habría que precisar esta situación

36 Vid. Reglamento de la Fiscalía de la Corte Penal Internacional.

37 Vid. Estatuto de Roma de 1998, Arts. 51 y siguientes, y Reglas de Procedimiento y Prueba.

Número de página no utilizable para citar 
respecto a los principales responsables, que son de ISIS, organización que acumula varias nacionalidades. En cualquier caso, también es posible aplicar la jurisdicción universal.

Cabe señalar que para la evaluación de la disposición del Estado para juzgar, se analiza si el proceso llevado a cabo fue con la intención de sustraer al sujeto de la competencia de la CPI, hubo una demora incompatible con la justicia, o el tribunal que juzga no da garantías de independencia e imparcialidad.

Por otro lado, para el análisis de la capacidad del Estado para juzgar, se analiza si el Estado puede o no hacer comparecer al imputado, dispone de pruebas necesarias o no está en condiciones de llevar a cabo el juicio, por un colapso total o sustancial de su Poder Judicial, o por carecer del mismo.

Suponiendo que conforme a lo que hemos comentado ya se ha sorteado este límite respetando el principio de complementariedad, de modo que Francia acepta el juicio por la Corte Penal Internacional y no por sus propios tribunales, con la ventaja de dar aplicación al Estatuto de Roma, y sin entrar aun a analizar el respeto al debido proceso en la legislación francesa frente a hechos que calificarían como terrorismo, este punto también debiese ser superado en el examen de admisibilidad.

Particularmente en el caso francés, habría que distinguir el juicio con respecto al autor inmediato (Abdeslam) y los mayores responsables del ISIS, pues si se trata del primero, lógicamente se puede hacer comparecer al imputado, puede disponer de las pruebas necesarias, puede llevar a cabo el juicio y tiene plenamente vigente su Poder Judicial, de manera que en ese caso el Estado sería capaz de juzgar, pero no así respecto de los principales mandos de ISIS, pues en ese caso no tiene posibilidad de hacer comparecer a los imputados, al menos hasta una vez finalizado el conflicto, y aun tampoco puede disponer de las pruebas necesarias.

Por otro lado, en el aspecto de la disposición, habría que analizar el debido proceso y particularmente la independencia e imparcialidad como elementos para definir la disposición de Francia de juzgar, cuestión que por espacio no entraremos a desarrollar.

b) El segundo caso se refiere a si el sujeto ya fue enjuiciado por tales hechos, por el principio del nen bis in ídem, que lógicamente en este caso no se daría este supuesto de inadmisibilidad; y

c) En el caso de que la causa no sea de gravedad suficiente, es decir, que no sea una conducta sistemática y de gran escala, y con gran alarma social, punto que también estaría superado según lo indicado respecto al examen preliminar de la Fiscalía.

De este modo, en síntesis en el aspecto procesal, la viabilidad de llevar a cabo esta tesis estaría dada, primero, por la consulta que se le haga a Francia sobre si quiere que sean juzgados estos imputados (tanto a Abdeslam como a los principales líderes de Daesh) por este hecho en Francia o por la Corte Penal Internacional; segundo, por la oportunidad en que se realice, considerando que la viabilidad del proceso estaría dada luego del término del conflicto, desde la perspectiva del examen preliminar que realiza la Fiscalía; y tercero, porque en esas circunstancias, el Estado francés efectivamente podría no tener la capacidad para juzgar, al menos a los principales 
responsables, por la dificultad de hacerlos comparecer y de tener las pruebas, y en el caso de Abdeslam, por el eventual cuestionamiento a su disposición de juzgar respetando el debido proceso, punto que tendría que analizarse en extenso en otra oportunidad, aunque es preferible, por realismo político, la simple aceptación del Gobierno francés de realizar este juicio.

Por lo tanto, en la oportunidad correspondiente (terminado el conflicto bélico), sería posible el juicio ante la Corte Penal Internacional, aceptando Francia dicho procedimiento, cumpliendo con las exigencias del examen preliminar de la Fiscalía y no estando en ninguna de las hipótesis de inadmisibilidad establecidas en el Estatuto de Roma y las Reglas de Procedimiento y Prueba para el examen de admisibilidad.

\section{Conclusiones}

A modo de conclusiones, destacamos cuatro ideas:

$1^{\circ}$ La persecución penal de estos hechos mediante su calificación como delito terrorista es jurídicamente inconveniente, considerando:

a) Su imprecisión típica a nivel internacional;

b) El tinte político inserto en estas figuras en las diversas legislaciones domésticas que, en caso de afectar también al debido proceso, establecen dos tipos de imputados disminuyendo las garantías en unos y manteniéndolas en otros, afectando con ello el Estado de Derecho, Social y Democrático (y con ello también los valores occidentales, cediendo a las pretensiones de quienes serían los terroristas);

c) Su naturaleza nacional o transnacional según si involucra o no a más de un Estado, aspecto que limita la jurisdicción y legislación aplicable excluyendo al Derecho Penal Internacional; y

d) La posibilidad de amnistías, inmunidades, prescripciones e indultos, o incluso asilos políticos, además de vulneraciones eventuales al debido proceso, o el establecimiento de la pena de muerte.

$2^{\circ}$ Resulta jurídicamente correcto la persecución penal internacional como crimen nuclear internacional, particularmente como crimen de guerra, considerando que efectivamente la Guerra de Siria constituye un conflicto bélico internacional aun cuando no sea entre dos Estados sino que contra una organización, considerando participación de Estados, territorios afectados y víctimas, concurren los elementos comunes de los crímenes de guerra (contexto, tipo de víctima, plan o política o comisión a gran escala, sin exigir evaluación jurídica del hechor) y concretamente, califican dentro de la figura de ataque a la población civil en conflicto internacional conforme a la letra b) del Art. 8.2, o bien, como ataque a la población civil como figura general conforme a la letra a) del Art. 8.2; 
$3^{\circ}$ Esta segunda posibilidad resulta más conveniente y jurídicamente correcto tanto desde la perspectiva normativa como de persecución penal y de debido proceso para el imputado, pues hace aplicable al Derecho Penal Internacional y con ello:

a) La competencia de la Corte Penal Internacional y el principio de jurisdicción universal;

b) Los procedimientos establecidos en el Estatuto de Roma y las Reglas de Procedimiento y Prueba que garantizan el respeto al debido proceso mediante etapa de admisibilidad, primera instancia o juicio contradictorio, y apelación;

c) Las penas proporcionales pero no inhumanas, descartando la pena de muerte;

d) El régimen jurídico sustantivo aplicable en cuanto al principio de reserva legal, respecto de la faz subjetiva de los tipos penales, la participación, y las circunstancias eximentes y modificatorias de responsabilidad penal; y

e) La exclusión de la prescripción, la amnistía, o los indultos.

$4^{\circ}$ Finalmente, esta segunda posibilidad resulta procesalmente viable, aunque en una oportunidad posterior una vez concluido el conflicto bélico, aceptando Francia dicho procedimiento considerando las ventajas de dar aplicación al Estatuto de Roma, cumpliendo con las exigencias del examen preliminar de la Fiscalía y no estando en ninguna de las hipótesis de inadmisibilidad establecidas en el Estatuto de Roma y las Reglas de Procedimiento y Prueba para el examen de admisibilidad. 